Article

\title{
Cobalt-Nickel-Boron Supported over Polypyrrole-Derived Activated Carbon for Hydrolysis of Ammonia Borane
}

\author{
Yongjin Zou 1,2,*, Yubo Gao 1,2, Cuili Xiang 1,2, Hailiang Chu ${ }^{1,2}$, Shujun Qiu 1,2, Erhu Yan ${ }^{1,2}$, \\ Fen Xu ${ }^{1,2}$, Chengying Tang ${ }^{1,2}$ and Lixian Sun ${ }^{1,2, *}$ \\ 1 Guangxi Key Laboratory of Information Materials, Guilin University of Electronic Technology, \\ Guilin 541004, China; tianbo0627@163.com (Y.G.); xiangcuili@guet.edu.cn (C.X.); \\ chuhailiang@guet.edu.cn (H.C.); qiushujun@guet.edu.cn (S.Q.); yeh@guet.edu.cn (E.Y.); \\ xufen@lnnu.edu.cn (F.X.); ctang@guet.edu.cn (C.T.) \\ 2 Guangxi Collaborative Innovation Center of Structure and Property for New Energy Materials, \\ Guilin 541004, China \\ * Correspondence: zouy@guet.edu.cn (Y.Z.); sunlx@guet.edu.cn (L.S.); \\ Tel.: +86-773-221-6607 (Y.Z.); Fax: +86-773-229-0129 (Y.Z.)
}

Academic Editor: Hugo F. Lopez

Received: 8 May 2016; Accepted: 27 June 2016; Published: 8 July 2016

\begin{abstract}
In this study, polypyrrole (PPy) nanofibers were used to synthesize a super-activated carbon material. A highly-dispersed Co-Ni-B catalyst was supported on PPy nanofiber-derived activated carbon (PAC) by chemical reduction. The Co-Ni-B/PAC hybrid catalyst exhibited excellent catalytic performance for the decomposition of ammonia borane $(\mathrm{AB})$ in an aqueous alkaline solution at room temperature. The size of the metal particles, morphology of Co-Ni-B/PAC, and catalytic activity of the supported catalyst were investigated. Ni-B, Co-B, and Co-Ni-B catalysts were also synthesized in the absence of PAC under similar conditions for comparison. The maximum hydrogen generation rate $\left(1451.2 \mathrm{~mL}^{-1} \cdot \mathrm{min}^{-1} \cdot \mathrm{g}^{-1}\right.$ at $\left.25^{\circ} \mathrm{C}\right)$ was obtained with Co-Ni-B/PAC. Kinetic studies indicated that the hydrolysis reaction of $\mathrm{AB}$ was first order with respect to Co-Ni-B/PAC, and the activation energy was $30.2 \mathrm{~kJ} \cdot \mathrm{mol}^{-1}$. Even after ten recycling experiments, the catalyst showed good stability owing to the synergistic effect of Co-Ni-B and PAC.
\end{abstract}

Keywords: hydrogen generation; ammonia borane; polypyrrole nanofiber; Co-Ni-B; hydrolysis

\section{Introduction}

The development of clean and renewable energy materials that can be used in automotive applications is an important issue, given the increasing worldwide demand for clean energy sources [1]. Hydrogen is considered a promising candidate to replace traditional fossil fuels because of its high energy efficiency and zero emissions [2]. However, the safe and proficient use of hydrogen is still a major technical barrier that prevents its on-board application. Catalyst-assisted hydrogen generation (HG) via decomposition of complex hydrides is the most studied approach for moving toward a hydrogen-powered society. Among these hydrides, ammonia borane $\left(\mathrm{AB}, \mathrm{NH}_{3} \mathrm{BH}_{3}\right)$ is a practical choice because it has a high hydrogen content (19.6 wt. \%), is soluble in water, can be safely stored, and is non-toxic. However, $\mathrm{AB}$ decomposition is sluggish without a catalyst [3-5]. Thus, it is necessary to choose suitable materials to accelerate the $\mathrm{AB}$ hydrolysis reaction; noble metal-based catalysts, such as $\mathrm{Ru}, \mathrm{Pd}$, and Pt, are commonly chosen [6-8]. However, limited resources and high cost hinder their widespread application, so considerable effort has been devoted to the exploration of efficient alternatives based on non-noble transition metals. For example, $\mathrm{Co}-\mathrm{B}, \mathrm{Cu}-\mathrm{Co}$, and Ni-Co nanoparticles were reported as active catalysts for AB hydrolysis [9-14]. However, metal nanoparticles 
easily aggregate due to their high surface energy, which reduces their surface area and the number of accessible active sites available for catalytic reactions [15].

To improve the stability and dispersity of metal nanoparticles, several routes have been adopted, mainly involving the introduction of transition metals during reduction or the use of supports with high specific surface area [16,17]. Compared to conventional support materials (e.g., SBA-15 [14], carbon black [18], $\mathrm{Al}_{2} \mathrm{O}_{3}$ [19], $\mathrm{SiO}_{2}$ [20], and $\mathrm{TiO}_{2}$ [21]), porous carbon materials are widely used in industrial applications due to their high surface area, good thermal and mechanical stabilities, chemical inertness, and high physisorption capacity [22-24]. Porous carbon materials have attracted attention in materials science and catalysis, and they have emerged as potential supports for growing and anchoring metal nanoparticles. Their mesoporous structure and unique nanoscale morphology could provide a high surface area for a high dispersion of catalyst nanoparticles and efficient transport of reactants. The performance of activated carbon is dependent on the selection of carbon source and activation conditions. Activated carbons prepared with petroleum coke, sawdust, bamboo, or leaves offer good performance as supporting catalysts [4]. However, polymer-derived porous carbon has not been well-studied as a support for non-noble metal catalysts for the hydrolysis of AB. On the other hand, the $\mathrm{N}$ dopant atom unavoidably modifies the local electronic structure and affects the physical and chemical properties of a new $\mathrm{N}$-doped carbon material. To date, it has been shown that the modification of carbon material by $\mathrm{N}$-doping alters the catalytic properties. Carbonization of $\mathrm{N}$-containing aromatic polymer materials, such as polyaniline (PANI) and polypyrrole (PPY), is considered to be an efficient way to prepare N-containing carbon materials/nanomaterials, most frequently with the preserved morphology of the PANI and PPY precursors. Compared with lignocellulosic biomass, the polymeric precursor can be more easily prepared under moderate and well-controlled conditions by using both template-based and template-free methods [25].

In this study, a polypyrrole (PPy) nanofiber-derived activated carbon (PAC)-supported Co-Ni-B catalyst was successfully synthesized by a chemical reduction method. Co-Ni-B supported on PAC has a high surface area with many active sites, thus showing excellent catalytic performance for HG via hydrolysis of $\mathrm{AB}$. Co-Ni-B/PAC is a remarkable catalyst that provides lower activation energy and improves the rate of the HG reaction. This low-cost and highly-efficient catalyst can be used as a potential hydrogen-storage material toward the application of $\mathrm{AB}$.

\section{Experimental Section}

\subsection{Materials}

Pyrrole (98\%), ammonium persulfate (APS) (99\%), cetyltrimethylammonium bromide (CTAB) $(>98 \%)$, ammonia borane $(\mathrm{AB}, 97 \%)$, sodium borohydride $\left(\mathrm{NaBH}_{4}, \geqslant 99 \%\right)$, cobalt sulfate heptahydrate $\left(\mathrm{CoSO}_{4} \cdot 7 \mathrm{H}_{2} \mathrm{O}, \geqslant 99 \%\right)$, and nickel sulfate hexahydrate $\left(\mathrm{NiSO}_{4} \cdot 6 \mathrm{H}_{2} \mathrm{O}, \geqslant 99 \%\right)$ were purchased from Aldrich Chemical Co., USA. All chemicals and reagents were used without further purification, except for pyrrole, which was distilled under reduced pressure before use. A Millipore Milli-Q deionizing system was used to obtain high purity water.

\subsection{Synthesis of the Catalyst}

The PPy nanofibers were synthesized according to a typical procedure previously reported in the literature [26]. CTAB $(1.82 \mathrm{~g})$, oxalic acid dehydrate $(0.63 \mathrm{~g})$, and pyrrole $(0.55 \mathrm{~mL})$ were dissolved in $250 \mathrm{~mL}$ deionized water at $25^{\circ} \mathrm{C}$ for $3 \mathrm{~h}$ under stirring. Next, $2 \mathrm{~g}$ APS was dissolved in $20 \mathrm{~mL}$ deionized water and slowly added dropwise to the prepared suspension using a burette. After stirring for $4 \mathrm{~h}$, the solution was filtered and washed thoroughly with deionized water and methanol, and dried under vacuum at $60^{\circ} \mathrm{C}$.

The obtained PPy nanofibers were further carbonized to fabricate carbonaceous nanoparticles in a quartz tubular furnace under a $\mathrm{N}_{2}$ atmosphere. The sample was gradually heated to $800^{\circ} \mathrm{C}$ at a heating rate of $3{ }^{\circ} \mathrm{C} \cdot \mathrm{min}^{-1}$, held at $800^{\circ} \mathrm{C}$ for $5 \mathrm{~h}$, and then cooled to room temperature. PAC was 
chemically activated by heating a PAC-KOH mixture $\left(\mathrm{KOH} / \mathrm{PAC}\right.$ at a weight ratio of 2:1) to $600{ }^{\circ} \mathrm{C}$ for $1 \mathrm{~h}$ under a $\mathrm{N}_{2}$ atmosphere.

The Co-Ni-B/PAC nanocomposite was prepared as follows. Typically, $5 \mathrm{~g} \mathrm{CoSO}_{4} \cdot 7 \mathrm{H}_{2} \mathrm{O}$ and $1 \mathrm{~g}$ $\mathrm{NiSO}_{4} \cdot 6 \mathrm{H}_{2} \mathrm{O}$ were dissolved in $100 \mathrm{~mL}$ deionized water, followed by addition of $0.1 \mathrm{~g}$ PAC, and the mixture was sonicated for $1 \mathrm{~h}$. The suspension was stirred vigorously in a $0{ }^{\circ} \mathrm{C}$ ice bath while $20 \mathrm{~mL}$ 10 wt. $\% \mathrm{NaBH}_{4}$ solution was added dropwise. A strong dark color was observed immediately after the addition of $\mathrm{NaBH}_{4}$. A schematic diagram of the process is shown in Figure 1. The black products were washed with distilled water and absolute ethanol three times successively by filtration, and then left to dry in a vacuum oven at $60{ }^{\circ} \mathrm{C}$ for $24 \mathrm{~h}$. For comparison, Ni-B, Co-B, and Co-Ni-B catalysts were synthesized in the absence of PAC under similar conditions.

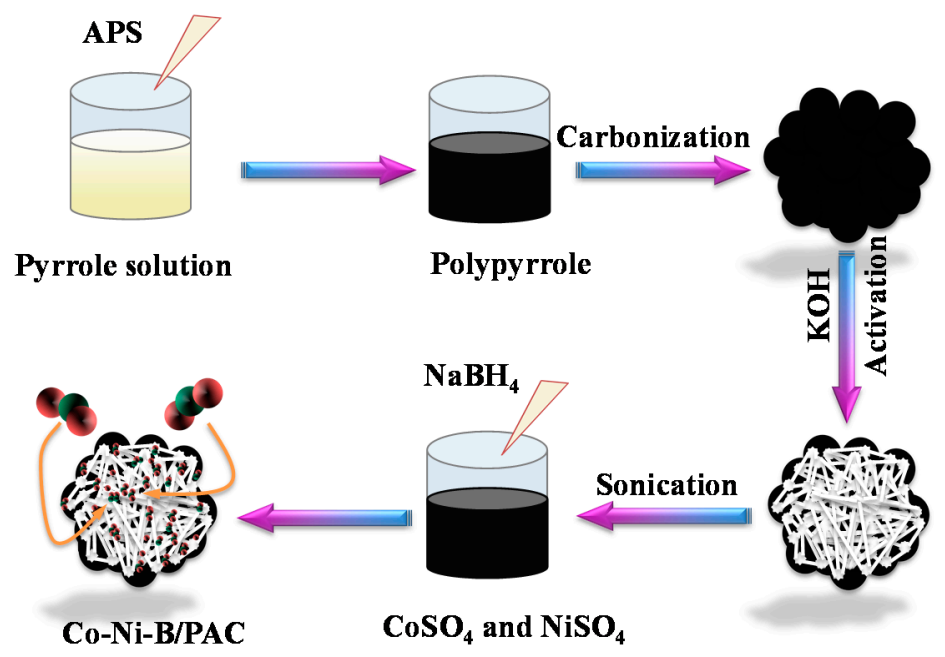

Figure 1. Schematic diagram showing the preparation of the Co-Ni-B/PAC nanocomposite.

\subsection{Characterization of the Catalyst}

Scanning electron microscopy (SEM) (S-4800, Hitachi, Tokyo, Japan) was used to characterize the morphology of the Co-Ni-B/PAC nanocomposite at an accelerating voltage of $10 \mathrm{kV}$. The morphologies and sizes of the catalysts were observed using transmission electron microscopy (TEM, JSM-200CX, JEOL, Tokyo, Japan). TEM samples were prepared by depositing one or two droplets of the synthesized catalyst suspensions onto copper grids. Powder X-ray diffraction (XRD) measurements were performed at room temperature $\left(25^{\circ} \mathrm{C}\right)$ using a diffractometer $(1820$, Philips, Eindhoven, The Netherlands) with $\mathrm{Cu} \mathrm{K} \alpha$ radiation $(\lambda=1.5418 \AA$ ). X-ray photoelectron spectroscopy (XPS) was performed using a SCIENTA ESCA250 instrument (Thermo Fisher Scientific, Waltham, MA, USA) equipped with a monochromatic Al K $\alpha(1486.6 \mathrm{eV}) \mathrm{X}$-ray source and a hemispherical analyzer. The specific surface areas of the catalysts were measured by $\mathrm{N}_{2}$ adsorption at $-196{ }^{\circ} \mathrm{C}$ using the Brunauer-Emmett-Teller (BET) method (Autosorb iQ2, Quantachrome Instruments, Boynton Beach, FL, USA). The samples were degassed at $150{ }^{\circ} \mathrm{C}$ until the vacuum pressure was below $10^{-4} \mathrm{~Pa}$. The average value of three measurements was taken for each sample.

\subsection{Hydrogen Generation Measurement}

Hydrogen generated by the catalytic decomposition of the AB solution was collected by the drainage method and expressed under standard conditions ( $1 \mathrm{~atm}$ and $25^{\circ} \mathrm{C}$ ). The HG volume was measured by water displacement (the weight of displaced water was recorded by a balance) [2]. In a typical measurement, $0.1 \mathrm{~g}$ catalyst was placed at the bottom of a sealed flask and a $1.5 \mathrm{wt}$. \% AB solution $(10 \mathrm{~mL})$ was injected into the flask. The temperature $\left(25,30,35\right.$, or $\left.40{ }^{\circ} \mathrm{C}\right)$ was controlled by immersing the flask in a water bath. The kinetics of AB hydrolysis catalyzed by Co-Ni-B/PAC 
were studied with respect to temperature, catalyst amount, and $\mathrm{AB}$ concentration. Changes to the $\mathrm{HG}$ rate determined the stability of the Co-Ni-B/PAC nanocomposite catalyst. After the HG reaction was complete, another equivalent of $\mathrm{AB}$ was added to the reaction system (each $\mathrm{AB}$ addition is considered as one test cycle).

\section{Results and Discussion}

\subsection{Characterization of the Catalysts}

An SEM image of the well-defined PPy nanofibers (Figure 2a) shows that their diameters were relatively uniform (average diameter $=50 \mathrm{~nm}$ ). The carbonized PPy nanofibers appear as spherical particles with diameters of 20-30 nm (Figure 2b). The synthesized Co-Ni-B/PAC composite (Figure 2c) had a globular morphology with diameters of 50-60 nm, approximately two times larger than those of PAC, indicating growth of the Co-Ni-B catalyst on the surface of PAC. From the TEM image (Figure 2d), it can be observed that the Co-Ni-B/PAC composite was composed of uniform, spherical nanoparticles. It is clear that Co-Ni-B was coated onto PAC. In contrast, the unsupported Co-Ni-B catalyst formed large particles (Figure S1), which could be due to particle agglomeration (the reaction between cobalt ions, nickel ions, and borohydride is strongly exothermic).
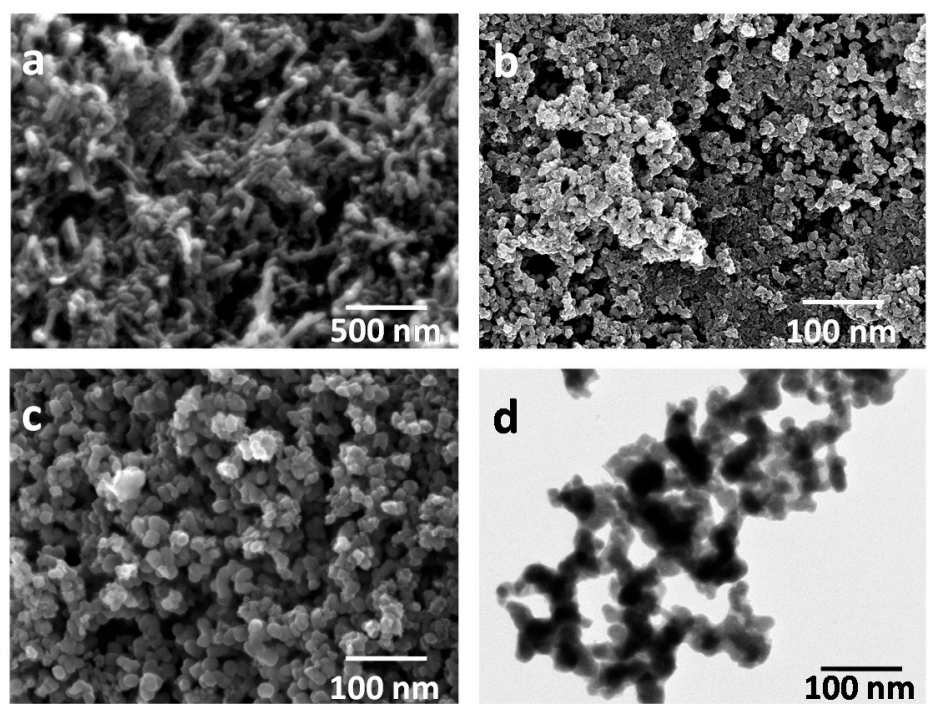

Figure 2. SEM images of (a) PPy (polypyrrole) nanofibers, (b) PAC (polypyrrole nanofiber-derived activated carbon) derived from PPy (polypyrrole), and (c) the Co-Ni-B/PAC nanocomposite; and (d) TEM image of the Co-Ni-B/PAC nanocomposite.

The as-synthesized catalysts were analyzed by powder XRD (Figure 3). No distinct peaks were observed for Co-Ni-B/PAC, which indicates that it was amorphous (an amorphous structure is expected to enhance its catalytic activity). A strong and broad peak around $45^{\circ}$ for Co-Ni-B can be assigned to the amorphous structure of the Co-Ni-B catalysts. The pattern of PAC shows two broad features centered at $2 \theta=24^{\circ}$ and $44^{\circ}$. These broad and low intensity diffraction bands are at positions where (002) and (101) diffraction peaks of graphitic carbon would occur [5].

XPS was performed to characterize the atomic composition of Co-Ni-B/PAC (Figure 4a). The XPS results confirm the presence of $\mathrm{Ni}, \mathrm{Co}, \mathrm{B}, \mathrm{C}, \mathrm{N}$, and $\mathrm{O}$ in the $\mathrm{Co}-\mathrm{Ni}-\mathrm{B} / \mathrm{PAC}$ composite. The binding energy at $398.8 \mathrm{eV}$ was attributed to uncharged pyrrolic nitrogen (Figure 4b) [6], which indicates that PAC was successfully doped into the Co-Ni-B catalyst. Figure 4c shows the high-resolution XPS spectrum of Co 2p; the peaks at 780.1 and $795.8 \mathrm{eV}$ correspond to Co 2p3/2 and Co 2p1/2, respectively. The observed Ni 2p3/2 and Ni 2p1/2 peaks with binding energies of 852.8 and $870.2 \mathrm{eV}$, respectively, correspond to metallic Ni (Figure $4 \mathrm{~d}$ ). Additional peaks were present at slightly higher energies 
compared to the Co $2 \mathrm{p}$ and $\mathrm{Ni} 2 \mathrm{p}$ bands, which reveals the existence of different oxidation states for these elements (likely occurred during the sample preparation process for the XPS measurements). XPS analysis also demonstrated that the surface molar composition of Co-Ni-B was $\mathrm{Co}_{47.5} \mathrm{Ni}_{14.4} \mathrm{~B}_{41.1}$.

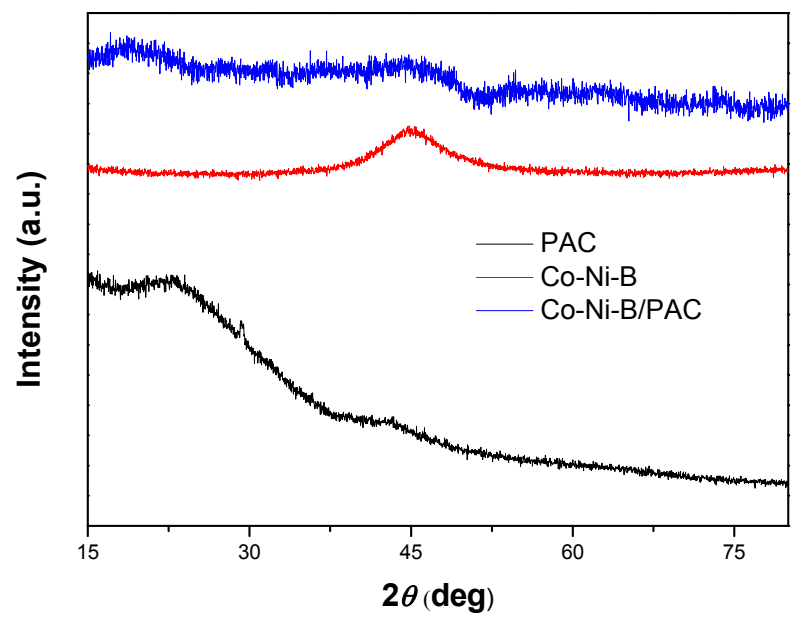

Figure 3. XRD patterns of PAC, Co-Ni-B, and Co-Ni-B/PAC powders.
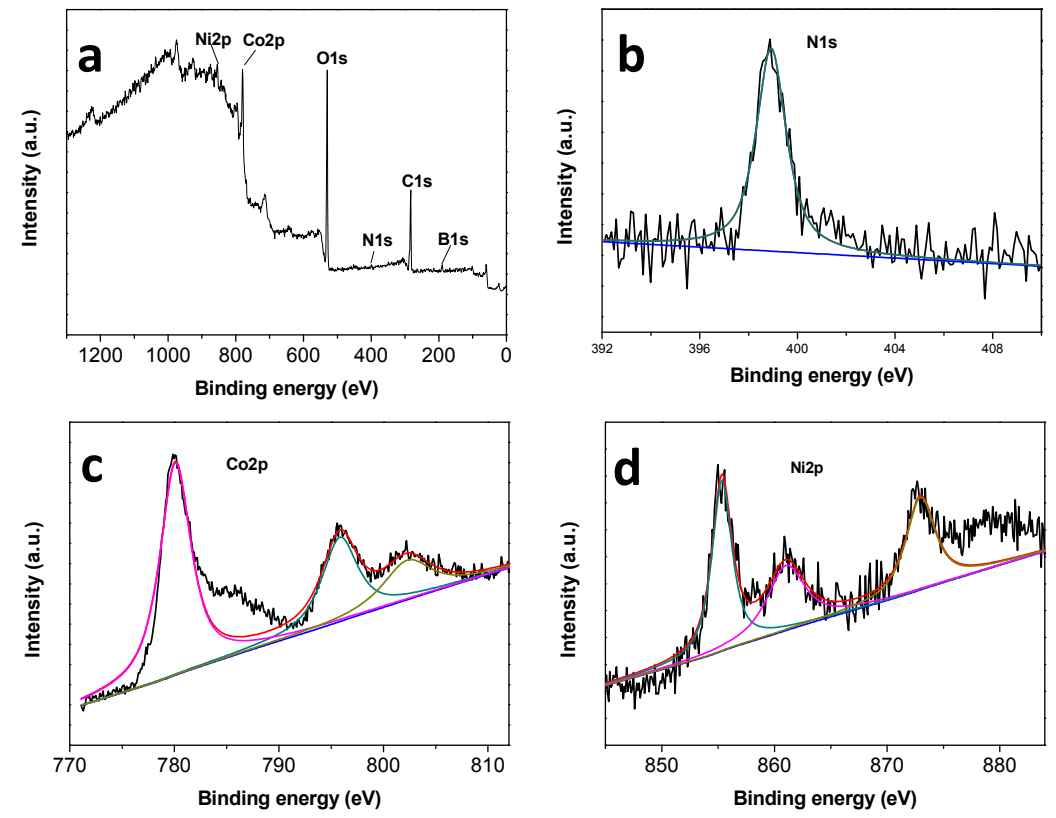

Figure 4. (a) Full XPS spectra of Co-Ni-B/PAC. XPS spectra of (b) N1s, (c) Co 2p, and (d) Ni 2p.

The specific surface areas are assumed to be crucial for the heterogeneous catalytic reaction. Nitrogen adsorption-desorption measurements were performed to obtain textural parameters (Figure 5). Non-doped Co-Ni-B samples had a relatively low specific surface area of $72 \mathrm{~cm}^{2} \cdot \mathrm{g}^{-1}$. The specific surface area drastically increased to $151 \mathrm{~m}^{2} \cdot \mathrm{g}^{-1}$ after doping with PAC derived from PPy nanofibers. The increase in surface area has to be attributed to the presence of the porous PAC support. In the low relative pressure region (below $P / P_{0}=0.15$ ), there was a large increase in the volume of adsorbed nitrogen, which indicates the development of microporosity. In addition, an obvious hysteresis loop emerged, providing evidence of a significant amount of mesopores in Co-Ni-B/PAC. These pores could provide reactants with access to the Co-Ni-B/PAC core, and products could easily exit through the pores [21]. 


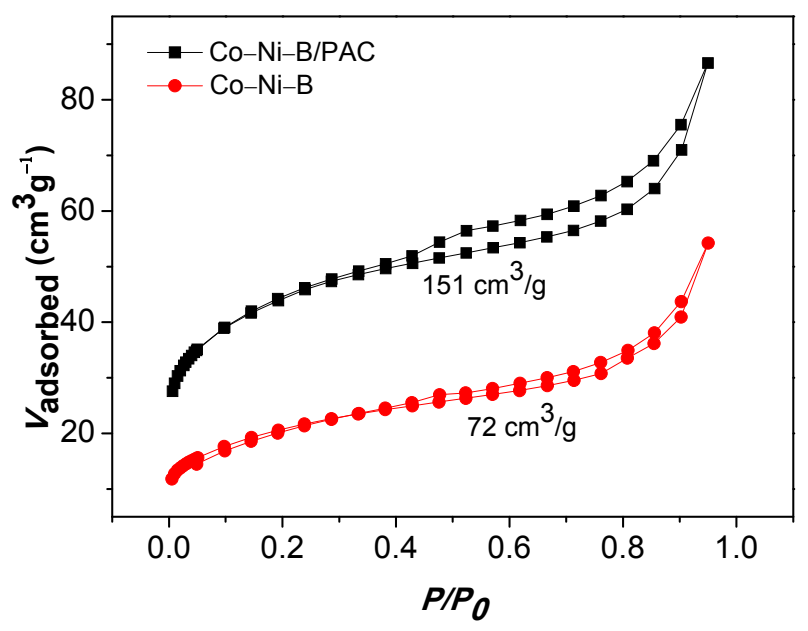

Figure 5. $\mathrm{N}_{2}$ adsorption and desorption isotherms of Co-Ni-B and Co-Ni-B/PAC powders.

\subsection{Effect of Different Types of Catalysts on Hydrogen Generation}

Alloy catalysts in the form of Co-P-B [27], Co-Mo-B [28], Co-W-B [29], and Co-Ni-B [30] exhibited better catalytic activity than $\mathrm{Co}-\mathrm{B}$. In the present study, $\mathrm{Co}-\mathrm{Ni}-\mathrm{B}$ was selected to coat PAC. The catalytic activity of the Co-Ni-B/PAC catalyst was tested for $\mathrm{H}_{2}$ production by hydrolysis of $\mathrm{AB}(1.5 \mathrm{wt}$. \%). The hydrogen yield was measured as a function of time in the presence of different catalysts $(0.1 \mathrm{~g})$ at $25{ }^{\circ} \mathrm{C}$. Figure 6 shows HG from the hydrolysis of $\mathrm{AB}$ catalyzed by Co-B, Ni-B, Co-Ni-B, and $\mathrm{Co}-\mathrm{Ni}-\mathrm{B} / \mathrm{PAC}$. Hydrogen was instantaneously produced when $\mathrm{AB}$ was exposed to each catalyst; $100 \%$ theoretical hydrogen yield was achieved for all catalysts. The HG rate decreased in the following order: Co-Ni-B/PAC $>$ Co-Ni-B $>$ Co-B $>$ Ni-B. The Co-Ni-B/PAC catalyst powder yielded the highest HG rate of $1451.2 \mathrm{~mL} \cdot \mathrm{min}^{-1} \cdot \mathrm{g}^{-1}$, which is about twice that obtained with the Co-Ni-B catalyst powder $\left(720.8 \mathrm{~mL} \cdot \mathrm{min}^{-1} \cdot \mathrm{g}^{-1}\right)$. In addition, the HG rate was higher than for other known catalysts, such as Pd nanoparticles supported on MIL-101 $\left(1008 \mathrm{~mL} \cdot \mathrm{min}^{-1} \cdot \mathrm{g}^{-1}\right)$ [31] and $\mathrm{Pt}_{3} \mathrm{Ni}\left(1388 \mathrm{~mL} \cdot \mathrm{min}^{-1} \cdot \mathrm{g}^{-1}\right)$ [32]. These results suggest that the synergistic interaction between $\mathrm{Co}-\mathrm{Ni}-\mathrm{B}$ and PAC may have contributed significantly to the hydrolysis of $\mathrm{AB}$. The Co-Ni-B nanoparticles were likely deposited onto the PAC nanoparticles in the special structure, providing an increased number of active sites on the surface because of its preferable expansion. These active sites may have also played a key role in the enhanced catalytic activity of the nanocomposite in the hydrolysis of $\mathrm{AB}$.

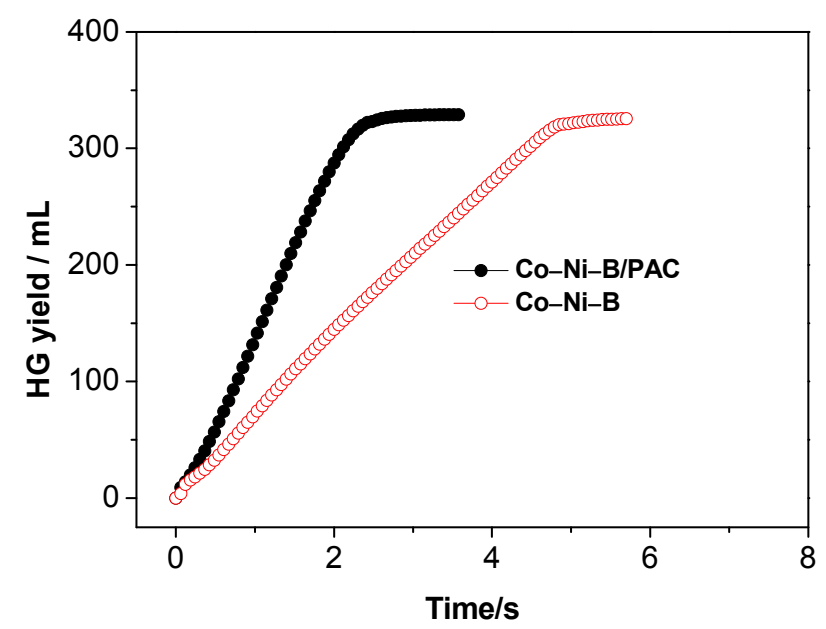

Figure 6. Hydrogen generation (HG) from hydrolysis of $\mathrm{AB}$ (ammonia borane) using the Co-Ni-B/PAC nanocomposite catalyst. (Batch system, $25^{\circ} \mathrm{C}, 1.5 \mathrm{wt}$ \% $\mathrm{AB}, 0.1 \mathrm{~g}$ catalyst). 


\subsection{Effect of Co/Ni Molar Ratio on Hydrogen Generation}

The effect of $\mathrm{Co} / \mathrm{Ni}$ molar ratio on the activity of the catalyst was investigated by changing the amount of $\mathrm{CoSO}_{4} \cdot 7 \mathrm{H}_{2} \mathrm{O}$ and $\mathrm{NiSO}_{4} \cdot 6 \mathrm{H}_{2} \mathrm{O}$ in the precursor solution. The catalytic activity of the Co-Ni-B catalyst is found to be dependent on the $\mathrm{Co} / \mathrm{Ni}$ ratio. As shown in Figure 7, the $\mathrm{HG}$ rate increased with respect to $\mathrm{Co} / \mathrm{Ni}$ molar ratio and reached a maximum value around 5 . Therefore, in the following sections, our investigation will focus on this Co-Ni-B catalyst with the optimized composition.

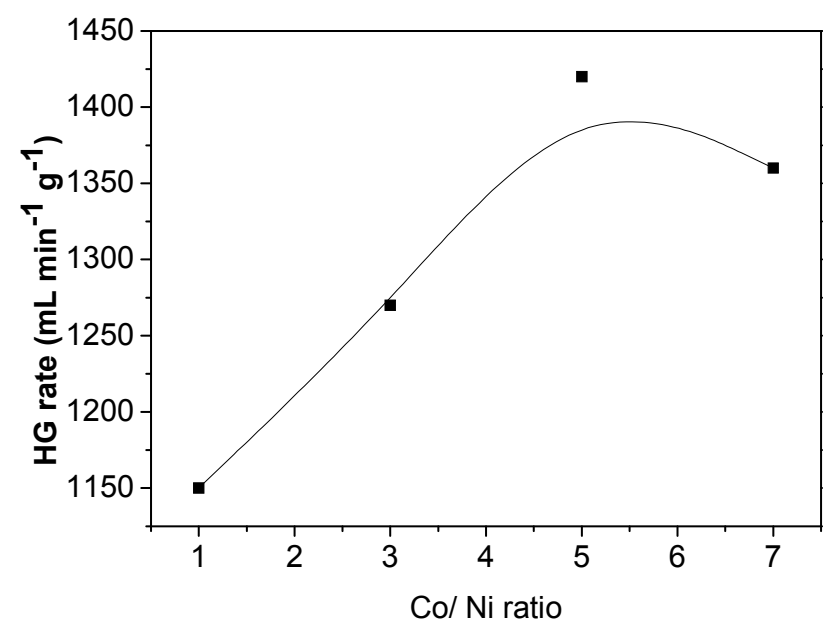

Figure 7. Effect of $\mathrm{Co} / \mathrm{Ni}$ molar ratio on the hydrogen generation $(\mathrm{HG})$ rate. (Batch system, $25{ }^{\circ} \mathrm{C}$, 1.5 wt. \% AB, $0.1 \mathrm{~g}$ catalyst).

\subsection{Effect of PAC Concentration on Hydrogen Generation}

The effect of PAC on the activity of the catalyst was investigated by changing the amount of PAC in the Co-Ni-B precursor solution in order to identify the effect of the supporting material on HG from hydrolysis. As shown in Figure 8, the HG rate increased with respect to PAC loading and reached a maximum value at $0.1 \mathrm{~g}$ PAC, above which the $\mathrm{HG}$ rate decreased. The surface of PAC was likely not completely coated by the Co-Ni-B catalyst when too much PAC was added or when PAC agglomerated in solution. Therefore, samples of the Co-Ni-B/PAC catalyst doped with $0.1 \mathrm{~g}$ PAC were used for all subsequent reactions performed in this study.

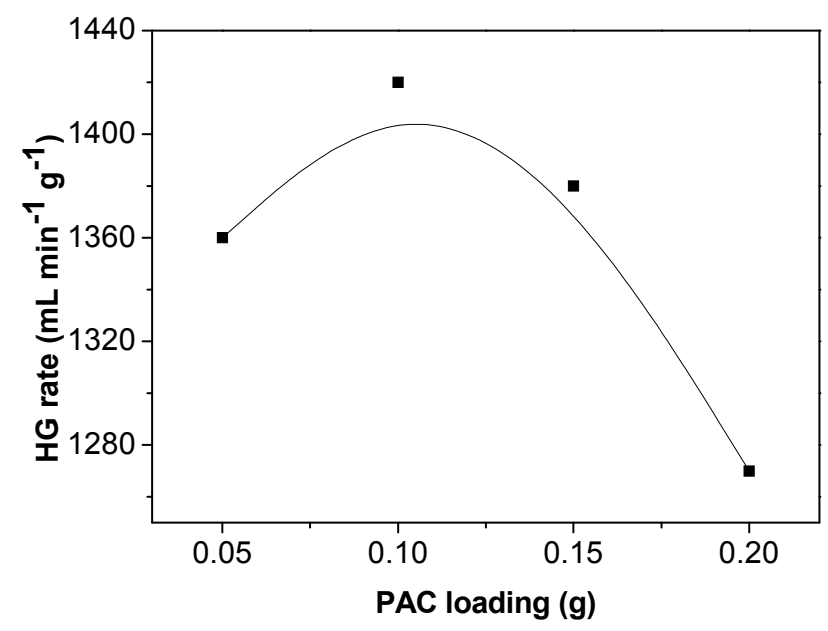

Figure 8. Effect of varying PAC concentration on the hydrogen generation (HG) rate. (Batch system, $25^{\circ} \mathrm{C}, 1.5$ wt. $\% \mathrm{AB}, 0.1 \mathrm{~g}$ catalyst). 


\subsection{Effect of the Amount of Catalyst on Hydrogen Generation}

A series of experiments was performed to study the kinetics of $\mathrm{AB}$ hydrolysis catalyzed by Co-Ni-B/PAC. Figure 9a shows HG versus reaction time during the hydrolysis of AB for different catalyst concentrations. HG proceeded at a rate that increased linearly with respect to the amount of catalyst (Figure 9b), demonstrating that the catalytic hydrolysis of $A B$ in the presence of the Co-Ni-B/PAC nanocomposite had a first-order relationship with respect to catalyst concentration.
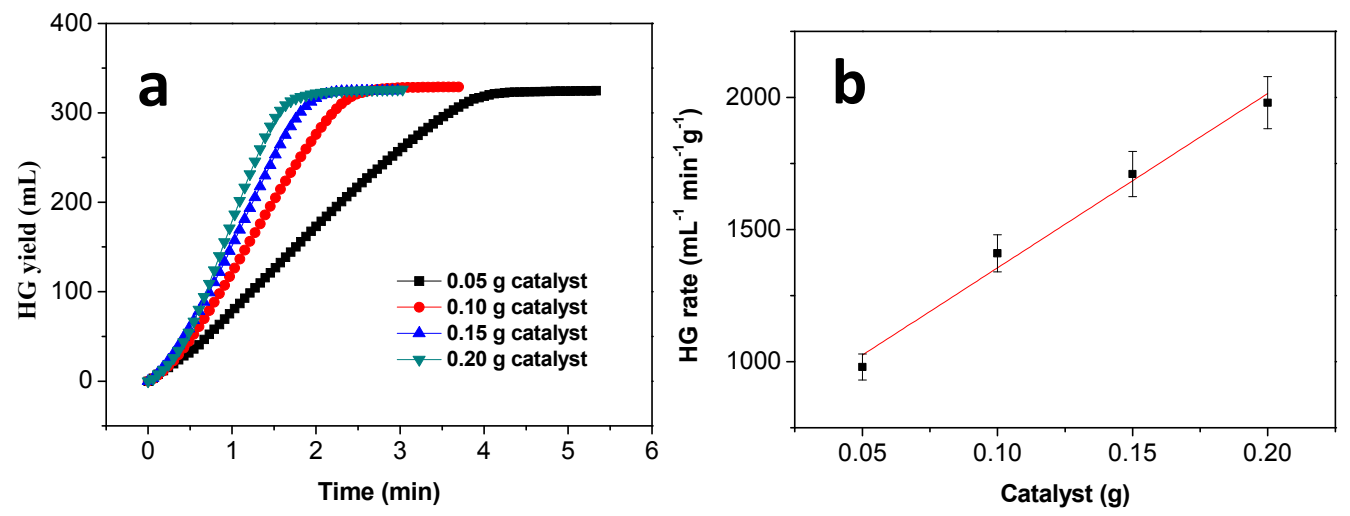

Figure 9. (a) Effect of reaction time on the hydrogen generation (HG) rate. (b) HG rate versus catalyst amount. (Batch system, $25^{\circ} \mathrm{C}, 1.5$ wt. \% AB).

\subsection{Effect of $A B$ Concentration on Hydrogen Generation}

The effect of $\mathrm{AB}$ concentration on the $\mathrm{HG}$ rate was studied by varying the initial concentration of the substrate (catalyst amount $=0.1 \mathrm{~g}$ ). Figure 10 shows the HG volume versus time for various initial concentrations of $\mathrm{AB}$. The $\mathrm{HG}$ rates remained almost constant with increasing $\mathrm{AB}$ concentration, indicating that the catalytic hydrolysis of $\mathrm{AB}$ was zeroth-order with respect to $\mathrm{AB}$ concentration.

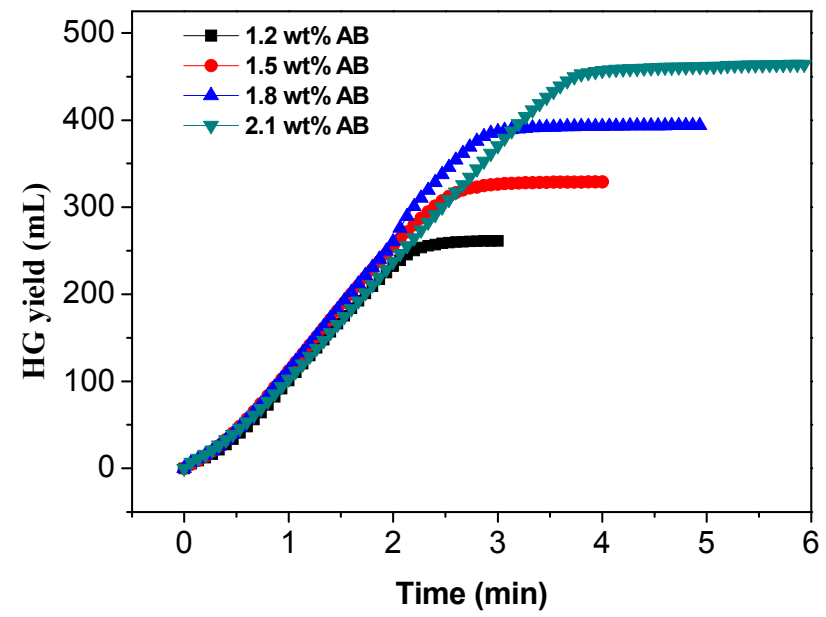

Figure 10. Effect of varying $\mathrm{AB}$ concentration on the hydrogen generation rate. (Batch system, $25^{\circ} \mathrm{C}$, 0.1 g catalyst).

\subsection{Kinetics of Hydrolysis Using Co-Ni-B/PAC}

The hydrolysis reaction was performed at different temperatures to determine the activation energy (Ea) for AB hydrolysis catalyzed by the Co-Ni-B/PAC nanocomposite. Figure 11a shows the $\mathrm{HG}$ yield versus reaction time for the hydrolysis of AB (1.5 wt. \%) catalyzed by the Co-Ni-B/PAC nanocomposite at temperatures between 25 and $40^{\circ} \mathrm{C}$. As expected, the $\mathrm{HG}$ rate increased with 
reaction temperature. The reaction rate constant, $k$, was calculated at each temperature from the slope of the linear part of each plot in Figure 10a. The Arrhenius plot of $\ln k$ versus $1 / T$ for the catalyst is shown in Figure 11b. From the slope of the straight line, $E a$ for the hydrolysis of AB in the presence of the Co-Ni-B/PAC nanocomposite was determined to be approximately $30.2 \mathrm{~kJ} \cdot \mathrm{mol}^{-1}$, which is lower than most reported Ea values for a variety of other catalysts for the hydrolysis reaction (Table 1). These results indicate that the Co-Ni-B/PAC nanocomposite exhibits superior catalytic performance.
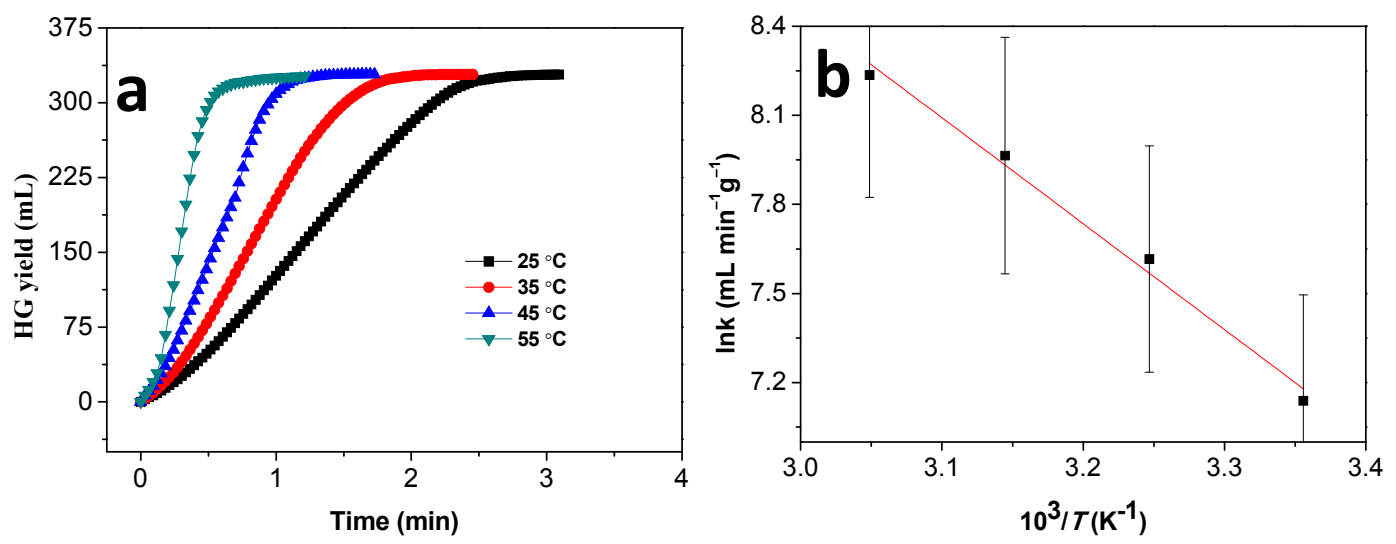

Figure 11. (a) HG kinetic curves at the initial stage of hydrolysis using $1.5 \mathrm{wt}$. \% AB solution and the Co-Ni-B/PAC catalyst at different solution temperatures. (b) Arrhenius plot of $\ln k$ (initial HG rate) versus the reciprocal of the absolute temperature $(1 / T)$.

Table 1. Comparison of the activation energy $\left(E_{\mathrm{a}}\right)$ for the hydrolysis of $\mathrm{AB}$ (ammonia borane) with various catalysts.

\begin{tabular}{|c|c|c|}
\hline Catalyst Sample & $E_{\mathrm{a}}\left(\mathrm{kJ} \cdot \mathrm{mol}^{-1}\right)$ & Ref. \\
\hline Cu@FeCo & 38.75 & {$[4]$} \\
\hline Fe-Ni/SBA-15 & 75 & [17] \\
\hline $\mathrm{Au} @ \mathrm{Pt}$ & 44.28 & [33] \\
\hline Ru-Rh@PVP a & $47.4 \pm 2.1$ & [34] \\
\hline $\mathrm{Cu}_{0.2} \mathrm{Co}_{0.8} / \mathrm{HPC}^{\mathrm{b}}$ & 41.7 & [35] \\
\hline $\mathrm{Cu} @ \mathrm{SiO}_{2}$ & $36 \pm 1$ & [36] \\
\hline $\mathrm{Rh} / \mathrm{CNTs}^{\mathrm{c}}$ & $32 \pm 1$ & {$[37]$} \\
\hline $\mathrm{Cu}-\mathrm{Cu}_{2} \mathrm{O}-\mathrm{CuO} / \mathrm{C}$ & 67.9 & [38] \\
\hline $\mathrm{Co}-\mathrm{Mo}-\mathrm{B} / \mathrm{Ni}$ & 44 & [39] \\
\hline NiCo-Pt & 45.72 & [40] \\
\hline Co-B & 47.5 & [41] \\
\hline Co-Ni-B/PAC & 30.2 & This work \\
\hline
\end{tabular}

\subsection{Stability of Co-Ni-B/PAC}

Aside from the catalytic activity, the recyclability of a catalyst is the other important factor that determines its potential application in practical HG systems. The recyclability of the Co-Ni-B/PAC catalyst was tested and satisfactory durability was observed. As shown in Figure 12, the catalytic activity of $\mathrm{Co}-\mathrm{Ni}-\mathrm{B} / \mathrm{PAC}$ in the hydrolysis of $\mathrm{AB}$ was retained at $86.7 \%$ of its initial value with complete release of hydrogen after 10 recover-and-reuse cycles. The stability of Co-Ni-B/PAC is higher than that of other catalysts, such as Ru-Rh@PVP (68\% of its initial activity after five recover-and-reuse cycles) [34] and intrazeolite Co nanoclusters (31\% activity loss in the fifth run) [42]. Thus, the Co-Ni-B/PAC nanocomposite exhibited high durability in the catalytic reactions. For powder-form Co or Co-containing catalysts, material loss is one of the most important factors during the process of separation and re-dispersion that causes a decrease in the subsequent activity of 
the catalysts [43]. In addition, the high surface energy and magnetic forces may cause fine powdery particles to aggregate during usage, isolation, and desiccation, which would result in a remarkable loss of long-term catalytic activity. In the present work, the Co-Ni-B nanoparticles were supported on the high surface area of PAC, which effectively hindered the loss of activity.

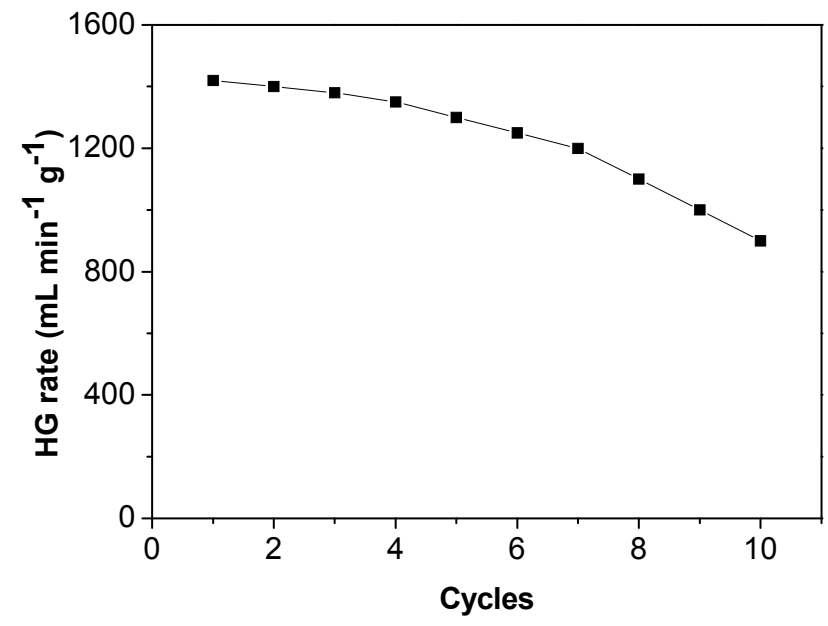

Figure 12. Multicycle operation of the Co-Ni-B/PAC catalyst employing a $1.5 \mathrm{wt}$. \% AB solution at $25^{\circ} \mathrm{C}$.

\section{Conclusions}

A Co-Ni-B/PAC nanocomposite was synthesized by in situ reduction using PPy-derived activated carbon as a supporting material. The Co-Ni-B/PAC nanocomposite showed significantly enhanced catalytic activity for $\mathrm{HG}$ via $\mathrm{AB}$ hydrolysis compared to the $\mathrm{Co}-\mathrm{Ni}-\mathrm{B}$ catalyst. The synergistic interaction between Co-Ni-B and PAC may have played a critical role in the enhanced catalytic activity. The Co-Ni-B/PAC nanocomposite showed exceptional stability and long-term stability for $\mathrm{HG}$ via AB hydrolysis. These results indicate that the $\mathrm{Co}-\mathrm{Ni}-\mathrm{B} / \mathrm{PAC}$ nanocomposite has the potential to be used as a reliable catalyst for the hydrolysis of $\mathrm{AB}$.

Supplementary Materials: The following are available online at www.mdpi.com/2075-4701/6/7/154/s1, Figure S1: TEM image of the Co-Ni-B catalyst.

Acknowledgments: The authors wish to express their gratitude and appreciation for the National Science Foundation of China (51561006, 51461011, 51261005, 51461010, 51401059, 51361005, 51371060, and U1501242), the Guangxi Natural Science Foundation (2014GXNSFAA118318, 2014GXNSFBA118240, 2015GXNSFBA139208 and 2015GXNSFAA139282), the Special Program of GUET Graduate Education Innovation Project for Reform and Development of Degrees and Graduate Education (JGY2015073) and the Innovation Project of Guangxi Graduate Education (YCSZ2015153).

Author Contributions: Y.Z. initiated the project. Y.Z. and L.S. designed and supervised the experimental work, which was performed by Y.G., C.L. and H.C. collected and analyzed the data. S.Q. and E.Y. participated in the data analysis. F.X. and C.T. were in charge of writing and checking the manuscript. All the authors read and approved the final manuscript.

Conflicts of Interest: The authors declare no conflict of interest.

\section{References}

1. Zhang, Z.; Lu, Z.H.; Chen, X. Ultrafine Ni-Pt alloy nanoparticles grown on graphene as highly efficient catalyst for complete hydrogen generation from hydrazine borane. ACS Sustain. Chem. Eng. 2015, 3, 1255-1261. [CrossRef]

2. Xiang, C.; Jiang, D.; She, Z.; Zou, Y.; Chu, H.; Qiu, S.; Zhang, H.; Xu, F.; Tang, C.; Sun, L. Hydrogen generation by hydrolysis of alkaline sodium borohydride using a cobaltezinceboron/graphene nanocomposite treated with sodium hydroxide. Int. J. Hydrog. Energy 2015, 40, 4111-4118. [CrossRef] 
3. Hu, L.; Zheng, B.; Lai, Z.; Huang, K.W. Room temperature hydrogen generation from hydrolysis of ammonia-borane over an efficient NiAgPd/C catalyst. Int. J. Hydrog. Energy 2014, 39, 20031-20037. [CrossRef]

4. Qiu, F.; Dai, Y.; Li, L.; Xu, C.; Huang, Y.; Chen, C.; Wang, Y.; Jiao, L.; Yuan, H. Synthesis of Cu@FeCo core-shell nanoparticles for the catalytic hydrolysis of ammonia borane. Int. J. Hydrog. Energy 2014, 39, 436-441. [CrossRef]

5. Shan, X.; Du, J.; Cheng, F.; Liang, J.; Tao, Z.; Chen, J. Carbon-supported $\mathrm{Ni}_{3} \mathrm{~B}$ nanoparticles as catalysts for hydrogen generation from hydrolysis of ammonia borane. Int. J. Hydrog. Energy 2014, 39, 6987-6994. [CrossRef]

6. Ma, H.; $\mathrm{Na}, \mathrm{C}$. Isokinetic temperature and size-controlled activation of ruthenium-catalyzed ammonia borane hydrolysis. ACS Catal. 2015, 5, 1726-1735. [CrossRef]

7. Li, Y.; Dai, Y.; Tian, X.K. Controlled synthesis of monodisperse $\mathrm{Pd}_{x} \mathrm{Sn}_{100-x}$ nanoparticles and their catalytic activity for hydrogen generation from the hydrolysis of ammonia-borane. Int. J. Hydrog. Energy 2015, 40, 9235-9243. [CrossRef]

8. Rakap, M. Poly(N-vinyl-2-pyrrolidone)-stabilized palladium-platinum nanoparticles-catalyzed hydrolysis of ammonia borane for hydrogen generation. J. Power Sources 2015, 276, 320-327. [CrossRef]

9. Chou, C.C.; Chen, B.H. Hydrogen generation from deliquescence of ammonia borane using Ni-Co/r-GO catalyst. J. Power Sources 2015, 293, 343-350. [CrossRef]

10. Zou, Y.; Cheng, J.; Wang, Q.; Xiang, C.; Chu, H.; Qiu, S.; Zhang, H.; Xu, F.; Liu, S.; Tang, C.; et al. Cobalt-boron/nickel-boron nanocomposite with improved catalytic performance for the hydrolysis of ammonia borane. Int. J. Hydrog. Energy 2015, 40, 13423-13430. [CrossRef]

11. Yao, Q.; Lu, Z.H.; Wang, Y.; Chen, X.; Feng, G. Synergetic catalysis of non-noble bimetallic Cu-Co nanoparticles embedded in $\mathrm{SiO}_{2}$ nanospheres in hydrolytic dehydrogenation of ammonia borane. J. Phys. Chem. C 2015, 119, 14167-14174.

12. Chandra, M.; Xu, Q. A high-performance hydrogen generation system: Transition metal-catalyzed dissociation and hydrolysis of ammonia-borane. J. Power Sources 2006, 156, 190-194. [CrossRef]

13. $\mathrm{Xu}, \mathrm{Q}$;; Chandra, M. Catalytic activities of non-noble metals for hydrogen generation from aqueous ammonia-borane at room temperature. J. Power Sources 2006, 163, 364-370. [CrossRef]

14. Zhu, Q.L.; Xu, Q. Liquid organic and inorganic chemical hydrides for high-capacity hydrogen storage. Energy Environ. Sci. 2015, 8, 478-512. [CrossRef]

15. Yen, H.; Seo, Y.; Kaliaguine, S.; Kleitz, F. Role of metal-support interactions, particle size, and metal-metal synergy in CuNi nanocatalysts for $\mathrm{H}_{2}$ generation. ACS Catal. 2015, 5, 5505-5511. [CrossRef]

16. Fernandes, R.; Patel, N.; Miotello, A.; Jaiswal, R.; Kothari, D.C. Dehydrogenation of ammonia borane with transition metal-doped Co-B alloy catalysts. Int. J. Hydrog. Energy 2012, 37, 2397-2406. [CrossRef]

17. Lai, S.W.; Lin, H.L.; Lin, Y.P.; Yu, T.L. Hydrolysis of ammonia-borane catalyzed by an iron-nickel alloy on an SBA-15 support. Int. J. Hydrog. Energy 2013, 38, 4636-4647. [CrossRef]

18. Liang, H.; Chen, G.; Desinan, S.; Rosei, R.; Rosei, F.; Ma, D. In situ facile synthesis of ruthenium nanocluster catalyst supported on carbon black for hydrogen generation from the hydrolysis of ammonia-borane. Int. J. Hydrog. Energy 2012, 37, 17921-17927. [CrossRef]

19. Rachiero, G.P.; Demirci, U.B.; Miele, P. Bimetallic RuCo and RuCu catalysts supported on gamma- $\mathrm{Al}_{2} \mathrm{O}_{3}$. A comparative study of their activity in hydrolysis of ammonia-borane. Int. J. Hydrog. Energy 2011, 36, 7051-7065. [CrossRef]

20. Yao, Q.; Shi, W.; Feng, G.; Lu, Z.H.; Zhang, X.; Tao, D.; Kong, D.; Chen, X. Ultrafine Ru nanoparticles embedded in $\mathrm{SiO}_{2}$ nanospheres: Highly efficient catalysts for hydrolytic dehydrogenation of ammonia borane. J. Power Sources 2014, 257, 293-299. [CrossRef]

21. Cheng, J.; Xiang, C.; Zou, Y.; Chu, H.; Qiu, S.; Zhang, H.; Sun, L.; Xu, F. Highly active nanoporous Co-B-TiO 2 framework for hydrolysis of $\mathrm{NaBH}_{4}$. Ceram. Int. 2015, 41, 899-905. [CrossRef]

22. Yao, Q.; Lu, Z.H.; Yang, K.; Che, X.; Zhu, M. Ruthenium nanoparticles confined in SBA-15 as highly efficient catalyst for hydrolytic dehydrogenation of ammonia borane and hydrazine borane. Sci. Rep. 2015, 5. [CrossRef] [PubMed]

23. Deng, S.; Hu, B.; Chen, T.; Wang, B.; Huang, J.; Wang, Y.; Yu, G. Activated carbons prepared from peanut shell and sunflower seed shell for high $\mathrm{CO}_{2}$ adsorption. Adsorption 2015, 21, 125-133. [CrossRef] 
24. Almasoudi, A.; Mokaya, R. Preparation and hydrogen storage capacity of templated and activated carbons nanocast from commercially available zeolitic imidazolate framework. J. Mater. Chem. 2012, 22, 146-152. [CrossRef]

25. Ćirić-Marjanović, G.; Pašti, I.; Gavrilov, N.; Janošević, A.; Mentus, S. Carbonised polyaniline and polypyrrole: Towards advanced nitrogen-containing carbon materials. Chem. Pap. 2013, 67, 781-813. [CrossRef]

26. Zou, Y.; Pisciotta, J.; Baskakov, I.V. Nanostructured polypyrrole-coated anode for sun-powered microbial fuel cells. Bioelectrochemistry 2010, 79, 50-56. [CrossRef] [PubMed]

27. Patel, N.; Kale, A.; Miotello, A. Improved dehydrogenation of ammonia borane over Co-P-B coating on Ni: A single catalyst for both hydrolysis and thermolysis. Appl. Catal. B Environ. 2012, 111-112, 178-184. [CrossRef]

28. Dai, H.B.; Gao, L.L.; Liang, Y.; Kang, X.D.; Wang, P. Promoted hydrogen generation from ammonia borane aqueous solution using cobalt-molybdenum-boron/nickel foam catalyst. J. Power Sources 2010, 195, 307-312. [CrossRef]

29. Dai, H.B.; Liang, Y.; Wang, P.; Yao, X.D.; Rufford, T.; Lu, M.; Cheng, H.M. High-performance cobalt-tungsten-boron catalyst supported on $\mathrm{Ni}$ foam for hydrogen generation from alkaline sodium borohydride solution. Int. J. Hydrog. Energy 2008, 33, 4405-4412. [CrossRef]

30. Xu, D.; Wang, H.; Guo, Q.; Ji, S. Catalytic behavior of carbon supported Ni-B, Co-B and Co-Ni-B in hydrogen generation by hydrolysis of $\mathrm{KBH}_{4}$. Fuel Process. Technol. 2011, 92, 1606-1610. [CrossRef]

31. Dai, H.M.; Su, J.; Hu, K.; Luo, W.; Cheng, G.Z. Pd nanoparticles supported on MIL-101 as high-performance catalysts for catalytic hydrolysis of ammonia borane. Int. J. Hydrog. Energy 2014, 39, 4947-4953. [CrossRef]

32. Yao, C.F.; Zhuang, L.; Cao, Y.L.; Ai, X.P.; Yang, H.X. Hydrogen release from hydrolysis of borazane on Pt- and Ni-based alloy catalysts. Int. J. Hydrog. Energy 2008, 33, 2462-2467. [CrossRef]

33. Park, J.W.; Lai, S.W.; Cho, S.O. Catalytic hydrogen generation from hydrolysis of ammonia borane using octahedral Au@Pt nanoparticles. Int. J. Hydrog. Energy 2015, 40, 16316-16322. [CrossRef]

34. Rakap, M. PVP-stabilized Ru-Rh nanoparticles as highly efficient catalysts for hydrogen generation from hydrolysis of ammonia borane. J. Alloy. Compd. 2015, 649, 1025-1030. [CrossRef]

35. Wang, H.; Zhou, L.; Han, M.; Tao, Z.; Cheng, F.; Chen, J. CuCo nanoparticles supported on hierarchically porous carbon as catalysts for hydrolysis of ammonia borane. J. Alloy. Compd. 2015, 651, 382-388. [CrossRef]

36. Yao, Q.; Lu, Z.H.; Zhang, Z.; Chen, X.; Lan, Y. One-pot synthesis of core-shell Cu@SiO 2 nanospheres and their catalysis for hydrolytic dehydrogenation of ammonia borane and hydrazine borane. Sci. Rep. 2014, 4. [CrossRef] [PubMed]

37. Yao, Q.; Lu, Z.H.; Jia, Y.; Chen, X.; Liu, X. In situ facile synthesis of Rh nanoparticles supported on carbon nanotubes as highly active catalysts for $\mathrm{H}_{2}$ generation from $\mathrm{NH}_{3} \mathrm{BH}_{3}$ hydrolysis. Int. J. Hydrog. Energy 2015, 40, 2207-2215. [CrossRef]

38. Yurderi, M.; Bulut, A.; Ertas, İ.E.; Zahmakiran, M.; Kaya, M. Supported copper-copper oxide nanoparticles as active, stable and low-cost catalyst in the methanolysis of ammonia-borane for chemical hydrogen storage. Appl. Catal. B Environ. 2015, 165, 169-175. [CrossRef]

39. Chen, X.; Li, H.; Luo, H.; Qiao, M. Liquid phase hydrogenation of furfural to furfuryl alcohol over Mo-doped Co-B amorphous alloy catalysts. App. Catal. A Gen. 2002, 233, 13-20. [CrossRef]

40. Wen, M.; Zhou, S.; Wu, Q.; Zhang, J.; Wu, Q.; Wang, C.; Sun, Y. Construction of NiCo-Pt nanopolyhedron inlay-structures and their highly efficient catalysis hydrolytic dehydrogenation toward ammonia borane. J. Power Sources 2013, 232, 86-92. [CrossRef]

41. Figen, A.K.; Coşkuner, B. A novel perspective for hydrogen generation from ammonia borane $\left(\mathrm{NH}_{3} \mathrm{BH}_{3}\right)$ with Co-B catalysts: “Ultrasonic Hydrolysis”. Int. J. Hydrog. Energy 2013, 38, 2824-2835. [CrossRef]

42. Rakap, M.; Özkar, S. Hydrogen generation from the hydrolysis of ammonia-borane using intrazeolite cobalt(0) nanoclusters catalyst. Int. J. Hydrog. Energy 2010, 35, 3341-3346. [CrossRef]

43. Liao, J.; Li, H.; Zhang, X. Preparation of Ti supported Co film composed of Co nanofibers as catalyst for the hydrolysis of ammonia borane. Catal. Commun. 2015, 67, 1-5. [CrossRef]

(C) 2016 by the authors; licensee MDPI, Basel, Switzerland. This article is an open access article distributed under the terms and conditions of the Creative Commons Attribution (CC-BY) license (http:/ / creativecommons.org/licenses/by/4.0/). 